\title{
CONCENTRAÇÃO DE METAIS EM UM SOLO ADUBADO COM ÁGUA RESIDUÁRIA DA BOVINOCULTURA DE LEITE
}

Jonathas Batista Gonçalves Silva' ${ }^{1}$, Mauro Aparecido Martinez ${ }^{2}$, Antônio Teixeira de Matos ${ }^{3}$, Adriana Paulo de Sousa Oliveira $^{4}$, Leonardo Batista Duarte da Silva ${ }^{5}$

\section{RESUMO}

Neste trabalho objetivou-se avaliar os efeitos do uso da água residuária da bovinocultura de leite (ARB) na concentração de metais em um argissolo cultivado com figueira (Ficus carica L.). O trabalho foi desenvolvido na área do Sistema Integrado de Produção Agroecológica, no município de Seropédica, RJ. O nitrogênio foi tomado como nutriente de referência na adubação da figueira com aplicação da ARB. Foram avaliados os seguintes parâmetros do solo: $\mathrm{Zn}, \mathrm{Cu}$, Fe e Mn disponíveis. Os dados obtidos foram submetidos à análise de variância e as médias comparadas utilizandose o teste de Tukey a $10 \%$ de significância. No que se refere aos teores de metais, observou-se que o uso da água residuária de bovinocultura na adubação da figueira foi capaz de reduzir a concentração dos elementos $\mathrm{Zn}, \mathrm{Cu}, \mathrm{Fe}$ e Mn que a princípio apresentavam-se em concentrações elevadas no solo, indicando níveis tóxicos. Ressalta-se que a matéria orgânica incorporada ao solo pode ter atuado na quelação e complexação, formado precipitados de baixa mobilidade dos micronutrientes $\mathrm{Zn}, \mathrm{Cu}, \mathrm{Fe}$ e $\mathrm{Mn}$.

Palavras-chave: fertirrigação, aproveitamento de água residuária, manejo orgânico

\section{ABSTRACT}

\section{CONCENTRATION OF METALS IN A FERTILIZED SOIL WITH WASTEWATERS OF DAIRY CATTLE}

In this work aimed to evaluate the effects of the use of wastewater from dairy cattle in the concentration of metals in a cultivated ultisol with fig (Ficus carica L.). The work was developed in the area of the Integrated Agroecological Production in the municipality of Seropédica, RJ. The nitrogen was used as a reference element in fertilization of the fig tree with application of wastewater from dairy cattle. We evaluated the following parameters of the soil $\mathrm{Zn}, \mathrm{Cu}, \mathrm{Fe}$ and $\mathrm{Mn}$ availables. The data were submitted to analysis of variance and means were compared using the Tukey test at $10 \%$ probability. Regarding the content of metal, it was observed that the use of wastewater of cattle in the fig tree fertilization was able to reduce the concentration of $\mathrm{Zn}$ elements $\mathrm{Cu}, \mathrm{Fe}$ and $\mathrm{Mn}$ that were in high concentrations in the soil indicating toxic levels. Also noteworthy that the organic matter incorporated into the soil may have acted in thechelation and complexation, forming precipitates of low mobility of $\mathrm{Zn}, \mathrm{Cu}, \mathrm{Fe}$ and $\mathrm{Mn}$.

Keywords: fertirrigation, use of wastewater, organic management

\section{Recebido para publicação em 12/04/2016. Aprovado em 27/06/2016.}

1 - Engenheiro Agrícola e Ambiental, Professor da UFJF, jonathas.silva@ufjf.edu.br

2 - Engenheiro Agrícola, Professor da UFV, mmauro@ufv.br

3 - Engenheiro Agrícola, Professor da UFMG, atmatos@desa.ufmg.br

4 - Engenheira Ambiental e Sanitarista, Mestranda UFRRJ, adriana.sousa@engenharia.ufjf.br

5 - Engenheiro Agrícola, Professor da UFRRJ, irriga@ufrrj.br 


\section{INTRODUÇÃO}

A quantidade de dejetos produzidos diariamente por bovinos de leite é um dos maiores problemas em confinamentos. A disposição dos resíduos das instalações animais tem se constituído num desafio para criadores e especialistas, pois envolve aspectos técnicos, sanitários e econômicos.

Segundo Carvalho e Silva (2006), na maioria dos confinamentos, com sistemas de limpeza hidráulica dos resíduos, o consumo de água é de 200 a 250 litros por unidade animal por dia. De acordo com os mesmos autores, a produção diária de esterco (fezes + urina) dos bovinos leiteiros é aproximadamente $10 \%$ de seu peso corporal, o que representa, na maioria dos casos, uma taxa de produção de 45 a $48 \mathrm{~kg} \mathrm{~d}^{1}$ por animal.

No que se refere às características qualitativas da água residuária da bovinocultura de leite, podese afirmar que a água é rica em material orgânico, sólidos totais e nutrientes, tais como nitrogênio e potássio (ERTHAL et al., 2010).

O lançamento direto de efluentes em corpos de água receptores deve atender a padrões estabelecidos pela legislação federal (Resolução CONAMA n ${ }^{\circ} 357 / 2005$ ), que estabelece normas e padrões da qualidade das águas e lançamentos de efluentes nas coleções de água.

Diante da degradação ambiental causada pelo lançamento de águas residuárias nas coleções de água e da ação fiscalizadora realizada por órgãos públicos responsáveis pela qualidade do meio ambiente, buscase soluções específicas no sentido de tratar, dispor ou aproveitar os resíduos (BARROS et al., 2005).

Uma das alternativas que se tem apontado para a resolução do problema é o uso dessas águas em áreas agricultáveis. $\mathrm{O}$ aproveitamento de águas residuárias na fertirrigação de culturas agrícolas pode possibilitar aumento de produtividade e qualidade dos produtos colhidos, redução da poluição ambiental e dos custos de produção, além de promover melhoria nas características químicas, físicas e biológicas do solo (BARROS et al., 2005; SANTOS et al., 2006). Todavia, o uso incorreto pode trazer efeitos deletérios tanto ao solo quanto à cultura.

Queiroz et al. (2004) verificaram redução de 36 $\%$ na concentração de $\mathrm{Cu}$ no solo após aplicação de água residuária de suinocultura. Freitas et al. (2005) verificaram que a acidez trocável do solo e a concentração de Fe decresceu em até 70 e $13 \%$, respectivamente, com a aplicação de água residuária de suinocultura. Segundo Carvalho e Caetano (2006), tal comportamento pode ser explicado pela complexação ou quelação do íon por ácidos orgânicos liberados pela matéria orgânica. Objetivou-se neste trabalho avaliar os efeitos da fertirrigação com água residuária de bovinocultura nas concentrações de metais em um Argissolo VermelhoAmarelo cultivado com figueira (Ficus carica L.).

\section{MATERIAL E MÉTODOS}

O trabalho foi desenvolvido na área do Sistema Integrado de Produção Agroecológica (SIPA), no município de Seropédica RJ. O solo da área experimental foi classificado como Argissolo VermelhoAmarelo por Carvalho et al. (2013). De acordo com Carvalho et al. (2012), o clima da região é classificado como Aw segundo Köppen, com temperaturas elevadas e chuvas no verão e um inverno seco com temperaturas amenas.

As amostras de solo foram coletadas antes da aplicação da ARB na área do experimento nas camadas de 00,20 e 0,400,60 m, a fim de se realizar a caracterização química deste, segundo os métodos descritos em EMBRAPA (2011). Após coletadas, as amostras foram secas ao ar e passadas em peneira de $2 \mathrm{~mm}$, sendo em seguida levadas ao Laboratório de Fertilidade e Rotina do Departamento de Solos da Universidade Federal de Viçosa (UFV). A caracterização química do solo incluiu $\mathrm{pH}$ em água, acidez trocável e potencial, matéria orgânica, capacidade de troca catiônica efetiva (CTCt) e potencial (CTCT), soma de bases (SB), saturação por alumínio (m), por bases (V) e sódio (ISNA), teores trocáveis de $\mathrm{Ca}, \mathrm{K}, \mathrm{Mg}$ e $\mathrm{Na}$, e disponível de P e Ntotal. No Quadro 1 apresentamse os resultados da análise de caracterização química do solo. 
Quadro 1. Caracterização química da amostra do Argissolo VermelhoAmarelo coletada nas camadas de 020 e 0,4060 m na área experimental do Sistema Integrado de Produção Agroecológica, antes da aplicação da água residuária de bovinocultura de leite

\begin{tabular}{lcclcc}
\hline Camadas $(\mathrm{m})$ & $0-0,20$ & $0,40-0,60$ & Camadas $(\mathrm{m})$ & $0-0,20$ & $0,40-0,60$ \\
\hline $\mathrm{pH} \mathrm{em} \mathrm{água}$ & 6,54 & 6,64 & $\mathrm{CTC}_{\mathrm{T}}\left(\mathrm{cmol}_{\mathrm{c}} \mathrm{dm}^{-3}\right)$ & 6,66 & 4,94 \\
$\mathrm{P}\left(\mathrm{mg} \mathrm{dm}^{-3}\right)$ & 149,10 & 50,80 & $\mathrm{Vs}(\%)$ & 64,00 & 67,60 \\
$\mathrm{~K}\left(\mathrm{mg} \mathrm{dm}^{-3}\right)$ & 153,00 & 89,00 & $\mathrm{~m}(\%)$ & 0,00 & 0,00 \\
$\mathrm{Na}\left(\mathrm{cmol}_{\mathrm{c}} \mathrm{dm}^{-3}\right)$ & 4,60 & 6,60 & $\mathrm{ISNA}(\%)$ & 0,47 & 0,86 \\
$\mathrm{Ca}\left(\mathrm{cmol}_{\mathrm{c}} \mathrm{dm}^{-3}\right)$ & 2,85 & 2,12 & $\mathrm{MO}\left(\mathrm{dag} \mathrm{kg}^{-1}\right)$ & 2,07 & 1,16 \\
$\mathrm{Mg}\left(\mathrm{cmol}_{\mathrm{c}} \mathrm{dm}^{-3}\right)$ & 1,00 & 0,96 & $\mathrm{Zn}\left(\mathrm{mg} \mathrm{dm}^{-3}\right)$ & 12,46 & 5,32 \\
$\mathrm{Al}\left(\mathrm{cmol}_{\mathrm{c}} \mathrm{dm}^{-3}\right)$ & 0,00 & 0,00 & $\mathrm{Fe}\left(\mathrm{mg} \mathrm{dm}^{-3}\right)$ & 55,40 & 67,90 \\
$\left.\mathrm{H}+\mathrm{Al}^{-3} \mathrm{cmol}_{\mathrm{c}} \mathrm{dm}^{-3}\right)$ & 2,40 & 2,10 & $\mathrm{Mn}\left(\mathrm{mg} \mathrm{dm}^{-3}\right)$ & 53,30 & 53,00 \\
$\mathrm{SB}\left(\mathrm{cmol}_{\mathrm{c}} \mathrm{dm}^{-3}\right)$ & 4,26 & 3,34 & $\mathrm{Cu}\left(\mathrm{mg} \mathrm{dm}^{-3}\right)$ & 5,95 & 3,48 \\
$\mathrm{CTC}\left(\mathrm{cmol}_{\mathrm{c}} \mathrm{dm}^{-3}\right)$ & 4,26 & 3,34 & $\mathrm{~N}\left(\mathrm{dag} \mathrm{kg}^{-1}\right)$ & 0,12 & 0,10 \\
\hline
\end{tabular}

- soma de bases (SB); capacidade de troca catiônica efetiva (CTCt); capacidade de troca catiônica potencial (CTCT), saturação por alumínio (m), saturação por bases (V) e índice de saturação por sódio (ISNA),

Foi utilizada ARB preparada a partir da mistura de esterco fresco proveniente do curral do SIPA e água de poço. No preparo da ARB foram realizadas análises das características dos dejetos provenientes do curral, de forma que a água residuária preparada apresentasse características semelhantes àquelas apresentadas por Erthal et al. (2010). Considerou-se a concentração de nitrogênio como a característica de referência no preparo do efluente. Em testes realizados, observou-se que a mistura de $15 \%$ de esterco fresco em $85 \%$ de água potável, foi aquela que proporcionou um efluente com características mais próximas àquelas citadas por Erthal et al. (2010). A caracterização da ARB foi realizada no Laboratório de Qualidade de Água do Departamento de Engenharia Agrícola da UFV, conforme métodos recomendados pela APHA (1995). Foram analisadas as seguintes características: $\mathrm{pH}$, condutividade elétrica (CE), sólidos totais (ST), demanda bioquímica de oxigênio (DBO), demanda química de oxigênio (DQO), nitrogênio total (Ntotal), nitrogênio amoniacal (NNH4) e concentrações totais de P, $\mathrm{Ca}, \mathrm{Mg}, \mathrm{K}, \mathrm{Na}, \mathrm{Fe}, \mathrm{Zn}$ e $\mathrm{Cu}$ e relação de adsorção de sódio (RAS). No Quadro 2 apresentam-se os resultados das análises realizadas na caracterização da ARB.

O nitrogênio foi tomado como nutriente de referência na adubação da figueira e as lâminas necessárias à aplicação das diferentes doses desse nutriente foram calculadas por meio da Equação 1 (MATOS, 2006).

$$
\mathrm{TA}_{\mathrm{AR}}=1000 \frac{\left[\mathrm{N}_{\mathrm{abs}}-\left(\mathrm{T}_{\mathrm{ml}} \cdot \mathrm{MO} \cdot \mathrm{p}_{\mathrm{g}} \cdot \mathrm{p} \cdot 10^{7} \cdot 0,05 \cdot \frac{\mathrm{n}}{12}\right)\right]}{\left[\mathrm{T}_{\mathrm{m} 2} \cdot \mathrm{N}_{\text {org }}+\left(\mathrm{N}_{\mathrm{amoniacal}}+\mathrm{N}_{\text {nitrato }}\right) \cdot \mathrm{TR}\right]}
$$

em que,

$\mathrm{TA}_{\mathrm{AR}}=$ lâmina de aplicação $\left(\mathrm{m}^{3} \mathrm{ha}^{-1}\right)$;

$\mathrm{N}_{\mathrm{abs}}=$ absorção de nitrogênio pela cultura para a obtenção da produtividade desejada ( $\left.\mathrm{kg} \mathrm{ha}^{1}\right)$;

$\mathrm{T}_{\mathrm{m} 1}=$ taxa anual de mineralização da matéria orgânica anteriormente existente no solo $\left(\mathrm{kg} \mathrm{kg}^{-1}\right.$ ano $^{-1}$ ) considerada $0,01 \mathrm{~kg} \mathrm{~kg}^{1}$ ano $^{1}$ (MATOS, 2006);

$\mathrm{MO}=$ conteúdo de matéria orgânica do solo $(\mathrm{kg}$ $\mathrm{kg}^{1}$ );

$\rho_{\mathrm{s}}=$ massa específica do solo $\left(\mathrm{t} \mathrm{m}^{3}\right)$;

$\mathrm{p}=$ profundidade de solo considerada (m), considerada $0,40 \mathrm{~m}$;

$\mathrm{n}$ = número de meses de cultivo da cultura, considerado 12 meses;

$\mathrm{T}_{\mathrm{m} 2}=$ taxa anual de mineralização do nitrogênio orgânico $\left(\mathrm{kg} \mathrm{kg}^{-1} \mathrm{ano}^{-1}\right)$, considerada $0,5 \mathrm{~kg} \mathrm{~kg}$ ${ }^{1}$ ano $^{1}$ (MATOS, 2006);

$\mathrm{N}_{\text {org }}=$ nitrogênio orgânico disponibilizado pelo resíduo aplicado $\left(\mathrm{mg} \mathrm{L}^{-1}\right)$;

$\mathrm{N}_{\text {amonical }}=$ nitrogênio amoniacal disponibilizado pelo resíduo aplicado $\left(\mathrm{mg} \mathrm{L}^{-1}\right)$;

$\mathrm{N}_{\text {nitrato }}=$ nitrogênio nítrico disponibilizado pelo resíduo aplicado $\left(\mathrm{mg} \mathrm{L}^{-1}\right)$, e

$\mathrm{TR}=$ taxa de recuperação do nitrogênio mineral pela cultura $\left(\mathrm{kg} \mathrm{kg}^{1}\right.$ ano ${ }^{1}$ ), considerada $0,70 \mathrm{~kg} \mathrm{~kg}^{1}$ ano $^{1}$ (MATOS, 2006). 
Quadro 2. Caracterização da água residuária da bovinocultura de leite preparada a partir da mistura de $15 \%$ de esterco fresco do curral do SIPA e $85 \%$ de água

\begin{tabular}{lccc}
\hline \multicolumn{1}{c}{ Características } & Valores médios & Desvio padrão & Valores obtidos por Erthal et al. (2010) \\
\hline $\mathrm{pH}$ & 6,48 & 0,34 & 7,84 \\
$\mathrm{CE}\left(\mathrm{mS} \mathrm{cm}^{-1}\right)$ & 2,91 & 0,61 & 4,26 \\
$\mathrm{ST}\left(\mathrm{mg} \mathrm{L}^{-1}\right)$ & 24.179 & 3.012 & 7.429 \\
$\mathrm{DQO}\left(\mathrm{m} \mathrm{L} \mathrm{L}^{-1}\right)$ & 26.875 & 12.590 & 16.539 \\
$\mathrm{DBO}\left(\mathrm{mg} \mathrm{L}^{-1}\right)$ & 3.522 & 1.914 & - \\
$\mathrm{N}-$ total $\left(\mathrm{mg} \mathrm{L}^{-1}\right)$ & 696,20 & 400,49 & 697,21 \\
$\mathrm{~N}-\mathrm{NH}^{-1}\left(\mathrm{mg} \mathrm{L}^{-1}\right)$ & 588,79 & 467,86 & - \\
$\mathrm{P}\left(\mathrm{mg} \mathrm{L}^{-1}\right)$ & 81,15 & 40,65 & 131,80 \\
$\mathrm{~K}\left(\mathrm{mg} \mathrm{L}^{-1}\right)$ & 123,13 & 48,10 & 361,98 \\
$\mathrm{Na}\left(\mathrm{mg} \mathrm{L}^{-1}\right)$ & 75,00 & 64,95 & 90,84 \\
$\mathrm{Ca}\left(\mathrm{m} \mathrm{L} \mathrm{L}^{-1}\right)$ & 210,10 & 192,33 & 123,25 \\
$\mathrm{Mg}\left(\mathrm{mg} \mathrm{L}^{-1}\right)$ & 137,55 & 110,23 & 32,44 \\
$\mathrm{RAS}\left(\mathrm{mmol}_{\mathrm{c}} \mathrm{L}^{-1}\right)^{1 / 2}$ & 1,39 & - & 1,03 \\
$\mathrm{Fe}\left(\mathrm{mg} \mathrm{L}^{-1}\right)$ & 9,65 & - & - \\
$\mathrm{Cu}\left(\mathrm{mg} \mathrm{L}^{-1}\right)$ & 6,25 & - & 1,32 \\
$\mathrm{Zn}\left(\mathrm{mg} \mathrm{L}^{-1}\right)$ & 1,00 & - & 2,94 \\
\hline
\end{tabular}

- condutividade elétrica (CE), sólidos totais (ST), demanda bioquímica de oxigênio (DBO), demanda química de oxigênio (DQO), nitrogênio total (Ntotal), nitrogênio amoniacal (NNH4), de adsorção de sódio (RAS).

As formulações de adubação aplicadas foram:

Adubação $1 \quad 100 \%$ da dose de nitrogênio recomendada para a figueira fornecida pela adubação com torta de mamona; Adubação $250 \%$ da dose de nitrogênio recomendada para a figueira fornecida por meio da adubação com ARB e os outros $50 \%$ da dose de nitrogênio fornecido juntamente com a adubação orgânica complementar; Adubação $375 \%$ da dose de nitrogênio recomendada para a figueira fornecida por meio da adubação com ARB e os outros $25 \%$ da dose de nitrogênio fornecido juntamente com a adubação orgânica complementar; Adubação 4
$100 \%$ da dose de nitrogênio recomendada para a figueira fornecida por meio da adubação com ARB. A quantidade de nitrogênio aplicada foi de $260 \mathrm{~g}$ cova $^{1}$ (433 $\mathrm{kg} \mathrm{ha}^{1}$, considerando 1666 plantas ha${ }^{1}$ ), segundo recomendação de Almeida e Silveira (1997).

Amostras da torta de mamona foram enviadas ao Laboratório de Matéria Orgânica e Resíduos do Departamento de Solos da UFV, para a realização de sua caracterização, segundo métodos descritos em APHA (2007). No Quadro 3 apresenta-se a caracterização química da torta de mamona.

Quadro 3. Caracterização química e física da torta de mamona utilizada na adubação complementar da figueira

\begin{tabular}{lllc}
\hline Parâmetro & Valor & Parâmetro & Valor \\
\hline C Total $(\%)$ & 37,55 & $\mathrm{Cu}\left(\mathrm{mg} \mathrm{kg}^{1}\right)$ & 4,00 \\
$\mathrm{Ca}(\%)$ & 0,48 & $\mathrm{Zn}\left(\mathrm{mg} \mathrm{cm}^{3}\right)$ & 53,30 \\
$\mathrm{Mg}(\%)$ & 0,18 & $\mathrm{Mn}\left(\mathrm{mg} \mathrm{cm}^{3}\right)$ & 43,80 \\
$\mathrm{~K}(\%)$ & 0,52 & $\mathrm{Fe}\left(\mathrm{mg} \mathrm{cm}^{3}\right)$ & $1.249,30$ \\
$\mathrm{P}(\%)$ & 0,35 & $\mathrm{Cd}\left(\mathrm{mg} \mathrm{cm}^{3}\right)$ & 0,60 \\
NTK$(\%)$ & 5,00 & $\mathrm{~Pb}$ & \\
Densidade $\left(\mathrm{mg} \mathrm{cm}^{3}\right)$ & 0,49 & $\mathrm{Cr}\left(\mathrm{mg} \mathrm{cm}^{3}\right)$ & 23,10 \\
pH & 5,75 & & \\
\hline
\end{tabular}

NTK Nitrogênio Total Kjeldahl 
Quadro 4. Lâminas médias da ARB e as doses de torta de mamona aplicadas por planta, considerando o somatório das quatro aplicações das distintas formulações de adubação

\begin{tabular}{ccc}
\hline Adubação & Lâmina de ARB $(\mathrm{mm})$ & Torta de mamona (kg por planta) \\
\hline Adubação 1 & 0,00 & 7,00 \\
Adubação 2 & 46,50 & 3,50 \\
Adubação 3 & 69,75 & 1,75 \\
Adubação 4 & 93,00 & 0,00 \\
\hline
\end{tabular}

Quadro 5. Quantidade total de nutrientes aportados às parcelas experimentais após a incorporação das adubações, considerando o somatório das quatro aplicações

\begin{tabular}{ccccc}
\hline \multirow{2}{*}{ Nutrientes } & \multicolumn{4}{c}{ Aporte $\left(\mathrm{kg} \mathrm{ha}^{-1}\right)$} \\
\cline { 2 - 5 } & Adubação 1 & Adubação 2 & Adubação 3 & Adubação 4 \\
\hline $\mathrm{N}$ & 433 & 433 & 433 & 433 \\
$\mathrm{P}$ & 40,82 & 26,42 & 19,23 & 12,03 \\
$\mathrm{~K}$ & 60,64 & 39,45 & 28,86 & 18,26 \\
$\mathrm{Ca}$ & 55,98 & 43,57 & 37,35 & 31,15 \\
$\mathrm{Mg}$ & 20,99 & 20,69 & 20,54 & 20,39 \\
$\mathrm{Fe}$ & 14,58 & 8,00 & 4,71 & 1,43 \\
$\mathrm{Cu}$ & 0,05 & 0,48 & 0,7 & 0,93 \\
$\mathrm{Zn}$ & 0,62 & 0,38 & 0,27 & 0,15 \\
$\mathrm{Mn}$ & 0,51 & 1,52 & 2,03 & 2,53 \\
\hline
\end{tabular}

A adubação foi parcelada em quatro épocas e a aplicação foi realizada nos meses de agosto, setembro e novembro de 2011 e fevereiro de 2012. Nos Quadros 4 e 5 apresentam-se, respectivamente, as lâminas médias da ARB e as doses de torta de mamona aplicadas por planta e a quantidade de nutrientes aportados às parcelas experimentais após a incorporação das diferentes adubações, considerando o somatório das quatro aplicações.

Após a colheita dos frutos da figueira, amostras de solo foram coletadas com o uso de um trado tipo rosca nas camadas de 00,20 e $0,400,60 \mathrm{~m}$, com a finalidade de verificar a variação dos micronutrientes $\mathrm{Zn}, \mathrm{Cu}, \mathrm{Fe}, \mathrm{Mn}$ disponíveis no solo, após a aplicação da ARB. Após a coleta, as amostras foram identificadas e enviadas aos Laboratórios de Rotina e de Física do Solo, do Departamento de Solos da UFV. As caracterizações foram realizadas segundo os métodos descritos em EMBRAPA (2011).

$\mathrm{O}$ experimento foi montado em esquema de parcelas subdivididas, tendo nas parcelas os tratamentos e nas subparcelas as duas profundidades de coletas de amostras, com o delineamento inteiramente casualizado e quatro repetições. Os dados foram submetidos à análise de variância. As médias foram comparadas utilizando-se o teste de Tukey a $10 \%$ de probabilidade. As análises estatísticas foram realizadas empregando-se o software SISVAR (FERREIRA, 2011).

\section{RESULTADOS E DISCUSSÃO}

No Quadro 6 apresentam-se as médias do teor de zinco disponível no solo determinadas nas camadas de 00,20 e 0,400,60 m, após as adubações.

Segundo a classificação proposta pela CFSEMG (1999) o teor de zinco disponível no solo, em todas as parcelas e em ambas as camadas, pode ser considerada alta, pois está acima de $2,2 \mathrm{mg} \mathrm{dm}$. A toxicidade do $\mathrm{Zn}$ pode provocar a diminuição da área foliar seguida de clorose e faz diminuir a absorção de fósforo e ferro (MALAVOLTA, 1980).

Diante dos resultados apresentados verificouse que o teor de zinco foi maior na Adubação 1 em relação as demais, na camada de 00,20 m. 
Quadro 6. Médias do teor de zinco disponível no solo, em $\mathrm{mg} \mathrm{dm}^{3}$, nas camadas de 00,20 e 0,400,60 m, após adubação

\begin{tabular}{ccc}
\hline \multirow{2}{*}{ Adubação } & \multicolumn{2}{c}{ Camada (m) } \\
\cline { 2 - 3 } & $0-0,20$ & $0,40-0,60$ \\
\hline Adubação 1 & $12,73 \mathrm{aA}$ & $4,70 \mathrm{aB}$ \\
Adubação 2 & $8,65 \mathrm{bA}$ & $2,56 \mathrm{aB}$ \\
Adubação 3 & $9,02 \mathrm{bA}$ & $4,29 \mathrm{aB}$ \\
Adubação 4 & $7,24 \mathrm{bA}$ & $2,13 \mathrm{aB}$ \\
\hline
\end{tabular}

Teor de Zn no solo antes da adubação

12,46

5,32

- as médias seguidas de pelo menos uma mesma letra minúscula na coluna e maiúscula na linha não diferem entre si em nível de 10\% de probabilidade pelo Teste de Tukey

Este resultado pode ser explicado pela maior incorporação deste elemento ao solo na Adubação $1\left(0,61 \mathrm{~kg} \mathrm{ha}^{1}\right)$, em relação às demais adubações $\left(0,38 ; 0,27\right.$ e $0,15 \mathrm{~kg} \mathrm{ha}^{1}$ nas Adubações 2,3 e 4, respectivamente), conforme apresentado no Quadro 5.

Nas demais adubações não foram verificadas diferença estatisticamente entre os tratamentos para a mesma camada. No entanto, nota-se que a Adubação 4 (100\% da dose de nitrogênio fornecida por meio da adubação com ARB) apresentou o menor teor de $\mathrm{Zn}$ no solo. Se comparado a concentração desse elemento antes do tratamento e após a Adubação 4 houve uma redução de cerca de $42 \%$ na camada de $00,20 \mathrm{~m}$. O mesmo comportamento foi observado na camada de 0,40 $0,60 \mathrm{~m}$ com a diminuição de $60 \%$ na concentração de zinco.

Resultados semelhantes foram observados por Lo Monaco et al. (2009), após aplicação de água residuária da cafeicultura (ARC) no solo. Os autores afirmaram que a redução do teor de zinco disponível no solo está associada à complexação do nutriente pela matéria orgânica presente no solo e àquela incorporada pelo efluente; à absorção pela cultura e possivelmente à sua lixiviação, uma vez que o zinco pode ter sido deslocado do complexo de troca pelo excesso de potássio presente na ARC. Diferentemente, Queiroz et al. (2004) verificaram aumento na concentração de zinco após aplicação de (água residuária de suinocultura) ARS em rampas de escoamento cultivada com forrageiras, após aporte de $1.738 \mathrm{~kg} \mathrm{ha}^{1}$ de zinco. No que se refere à variação do teor de zinco entre as camadas do solo monitoradas, observou-se que em todas as adubações o valor deste micronutriente foi maior na profundidade mais superficial. Segundo Dechen e Nachtigall (2006), no solo, o zinco é encontrado nos horizontes superficiais, o que está relacionado ao fato de que: a) os resíduos das plantas se depositam na superfície e pela decomposição, originam pequenas quantidades deste elemento; $b$ ) o zinco apresenta baixa mobilidade descendente no perfil, diferentemente de outros elementos, devido à capacidade de ser fixado pela matéria orgânica, pelas argilas e pelos óxidos e hidróxidos de ferro.

De acordo com a Resolução CONAMA 420/2009, que determina os valores orientadores quanto a presença de substancias químicas no solo em decorrência de atividades antrópicas, a concentração de zinco não deve superar $450 \mathrm{mg} \mathrm{kg}^{1}$ para uso agrícola (BRASIL, 2009). A Comunidade Europeia, através do European Council Directive 86/278/EEC e a legislação norte americana 40 CFR Part 503 estabelecem os limites de metais pesados a serem atingidos no solo após aplicação de lodo de estação de tratamento de esgoto (ETE) (USEPA, 1996). A Directive 86/278/EEC determina que a concentração de zinco não deve superar valores que variam de 150 a $300 \mathrm{mg} \mathrm{kg}^{1}$ a depender do $\mathrm{pH}$ do solo e a 40 CFR Part 503 limita os teores de Zn em $2.800 \mathrm{mg} \mathrm{kg}^{1}$. Os resultados encontrados para a presença de $\mathrm{Zn}$ no solo atendem as legislações citadas.

No Quadro 7 apresentam-se as médias do teor de cobre disponível no solo determinadas nas camadas de 00,20 e 0,400,60 m, após as adubações.

\section{REVENG}


Quadro 7. Médias do teor de cobre disponível no solo, em $\mathrm{mg} \mathrm{dm}^{3}$, determinadas nas camadas de 00,20 e 0,400,60 m, após adubação

\begin{tabular}{ccc}
\hline \multirow{2}{*}{ Adubação } & \multicolumn{2}{c}{ Camada (m) } \\
\cline { 2 - 3 } & $0-0,20$ & $0,40-0,60$ \\
\hline Adubação 1 & $4,66 \mathrm{aA}$ & $2,37 \mathrm{aB}$ \\
Adubação 2 & $4,43 \mathrm{aA}$ & $1,67 \mathrm{aB}$ \\
Adubação 3 & $4,92 \mathrm{aA}$ & $2,51 \mathrm{aB}$ \\
Adubação 4 & $3,55 \mathrm{aA}$ & $1,11 \mathrm{aB}$ \\
\hline Teor de Cu no solo antes da adubação & 5,95 & 3,48
\end{tabular}

- as médias seguidas de pelo menos uma mesma letra minúscula na coluna e maiúscula na linha não diferem entre si em nível de $10 \%$ de probabilidade pelo Teste de Tukey

Segundo a classificação proposta pela CFSEMG (1999), para a interpretação da disponibilidade de micronutrientes no solo, os teores de cobre disponíveis foram altos (maior que $1,8 \mathrm{mg} \mathrm{dm}^{3}$ ) em ambas as camadas e em todas as parcelas, exceto apenas para as Adubações 2 e 4 na camada de 0,40 $0,60 \mathrm{~m}$. A toxidez de cobre manifesta-se em menor crescimento, funcionamento anormal das raízes e aparecimento de manchas amareladas (FAQUIN, 2005).

Nachtigall et al. (2007) verificaram altos teores de cobre total em dois solos cultivados com vinhedos da região da Serra do Rio Grande do Sul, o que se deve ao fato de que o manejo de muitos dos vinhedos brasileiros envolver o uso contínuo de calda bordalesa $\left(\mathrm{CuSO}_{4}+\mathrm{Ca}(\mathrm{OH})_{2}\right)$ e de outros produtos a base de cobre, no controle de doenças em vinhedos cultivados por longos períodos. Diante disso, ressalta-se que o controle da ferrugem (Ceroteliumfici) e da antracnose (Colletotrichum gloesporioides), fungos que atacam as folhas das figueiras, foi realizado com a aplicação da calda bordalesa, desde o ano 2008, quando foi instalado o cultivo desta cultura na área experimental do SIPA.

Diante dos resultados, verificou-se que não ocorreu diferença do valor de cobre no solo entre as parcelas experimentais após a aplicação das adubações nas duas camadas estudadas, mesmo sendo verificado maior aporte deste elemento nas Adubações com maiores lâminas de ARB, conforme apresentado no Quadro 5.

Comparando-se os resultados obtidos após a adubação da cultura da figueira com ARB, verificouse que ocorreu diminuição do teor de cobre disponível no solo. Acredita-se que essa redução está associada à absorção do micronutriente pelas plantas e pela ocorrência da complexação/quelação do cobre pela matéria orgânica presente no solo e pela incorporada pela torta de mamona e pela ARB.

Queiroz et al. (2004) realizaram a disposição de ARS em rampas de escoamento e verificaram que o cobre teve sua concentração diminuída, indicando que este nutriente pode ter sido extraído pela cultura, ou tornou-se menos disponível em razão da complexação pela matéria orgânica, após aporte de $140 \mathrm{~kg} \mathrm{ha}^{1}$ de cobre ao solo. Resultado diferente foi obtido por Lo Monaco et al. (2009) que verificaram aumento na concentração do cobre após adubação do cafeeiro com ARC. Os autores acreditam que esse aumento na concentração de cobre na camada 00,20 $\mathrm{m}$ possa ser atribuído à mineralização da matéria orgânica do solo, disponibilizando o cobre que nela estava quelado/complexado ou advindo da própria água residuária.

Os teores de cobre disponível no solo foram maiores nas amostras coletadas na camada mais superficial, em todas as parcelas. Isto se deve ao fato do cobre ser pouco móvel ao longo do perfil do perfil do solo (MALAVOLTA, 1980). O Cu possui alta afinidade com a matéria orgânica e com os óxidos de $\mathrm{Fe}$ e $\mathrm{Al}$, por isso tem o seu transporte bastante reduzido em relação aos micronutrientes $\mathrm{Zn}, \mathrm{Fe}$ e Mn (PEGORARO et al., 2006).

A Resolução CONAMA 420/2009 limita a concentração de $\mathrm{Cu}$ em $200 \mathrm{mg} \mathrm{kg}{ }^{1}$, a Directive 86/278/EEC determina que a concentração de cobre não deve superar valores que variam de $50 \mathrm{a}$ $140 \mathrm{mg} \mathrm{kg}^{1}$ a depender do $\mathrm{pH}$ do solo, e para a 40 CFR Part 503 a presença de $\mathrm{Cu}$ deve ser inferior a 
$1.500 \mathrm{mg} \mathrm{kg}^{1}$. Os teores de $\mathrm{Cu}$, após as adubações, atendem a essas restrições.

No Quadro 8 apresentam-se as médias do teor de ferro disponível no solo determinadas nas camadas de 00,20 e 0,400,60 m, após as adubações.

Segundo a classificação de disponibilidade proposta pela CFSEMG (1999), observou-se que o teor de ferro na parcela submetida à Adubação 1 pode ser considerado bom, nas demais, o teor de ferro disponível estava alto, na camada de 00,20 m. Na camada de 0,400,60 m, verificou-se que nas parcelas submetidas a Adubação 4 o teor de ferro disponível foi médio, naquelas submetidas a Adubação 1 e 3 é bom e na Adubação 2 é alto.Os mesmo autores afirmam ainda que valores acima de $30 \mathrm{mg} \mathrm{dm}^{3}$ podem indicar nível crítico.

Assim como o $\mathrm{Zn}$, o maior aporte de $\mathrm{Fe}$ ao solo foi na Adubação $\left.1(14,58 \mathrm{~kg} \mathrm{ha})^{1}\right)$, em relação às demais adubações $\left(8,00 ; 4,71\right.$ e $1,43 \mathrm{~kg} \mathrm{ha}^{1}$ nas Adubações 2, 3 e 4, respectivamente), conforme apresentado no Quadro 5. No entanto, na camada de $0-0,20 \mathrm{~m}$, a Adubação 1 apresentou menor teor de ferro disponível. No solo a energia de adsorção do $\mathrm{Fe}$ com os colóides é maior que outros elementos como o $\mathrm{Ca}, \mathrm{Mg}, \mathrm{K}$ e $\mathrm{Na}$, assim o ferro pode deslocar esses elementos e adsorver-se aos colóides afim de manter o equilíbrio químico entre a fase sólida e a líquida(efeito tampão) o que reduz a concentração de ferro solúvel.

$\mathrm{Na}$ camada de 0,40-0,60 m, verificou-se que, apenas na Adubação 4 ocorreu diferença do teor de ferro disponível no solo entre as camadas monitoradas. Este resultado pode ser explicado pela baixa mobilidade do ferro no perfil do solo e pelo fato da incorporação da ARB ter sido realizada superficialmente. Nessa parcela a concentração de
Zn é menor, portanto ocorre menor interferência desse elemento na absorção de Fe.

De acordo com os resultados observou-se que nas parcelas submetidas à Adubação 2 foi maior em relação àquele obtido nas Adubações $1,3 \mathrm{e}$ 4 para ambas as camadas. Mas, ao comparar os resultados obtidos com o teor de ferro disponível no solo antes da aplicação das adubações, verificou-se redução dos teores deste elemento nas parcelas submetidas às adubações. Este resultado está associado à absorção do ferro disponível pela cultura ou ainda pela complexação pelo material orgânico incorporado pelas adubações.

Diferente do obtido neste trabalho, Lo Monaco et al. (2009) verificaram aumento na concentração do ferro após a adubação do cafeeiro com ARC. Os autores afirmam que em razão da aplicação de maior quantidade de material orgânico e água, pode ter ocorrido diminuição na disponibilidade de oxigênio no meio, em razão do seu consumo na decomposição dessa matéria orgânica. Logo, sendo o meio redutor, pela menor disponibilidade de oxigênio, ocorreu a redução do $\mathrm{Fe}^{3+}$ para $\mathrm{Fe}^{2+}$, o que proporcionou maior disponibilização de ferro no solo.

Nos solos, os teores de manganês geralmente encontram-se na faixa de 20 a $3000 \mathrm{mg} \mathrm{kg}^{1}$, com média de $60 \mathrm{mg} \mathrm{kg}^{1}$ (LINDSAY, 1979). Os principais fatores do solo que determinam a disponibilidade de manganês são o pH, as condições de óxidoredução, os teores de matéria orgânica e o equilíbrio com outros cátions, principalmente o ferro, cálcio e o magnésio (DECHEN e NACHTIGALL, 2006). No Quadro 9 apresentam-se as médias do teor de manganês disponível no solo determinadas nas camadas de 00,20 e 0,400,60 m, após adubações.

Quadro 8. Médias do teor de ferro disponível no solo, em $\mathrm{mg} \mathrm{dm}^{3}$, nas camadas de 00,20 e 0,400,60 m, após adubação

\begin{tabular}{ccc}
\hline Adubação & \multicolumn{2}{c}{ Camada (m) } \\
\cline { 2 - 3 } & $0-0,20$ & $0,40-0,60$ \\
\hline Adubação 1 & $34,22 \mathrm{bA}$ & $35,78 \mathrm{aA}$ \\
Adubação 2 & $57,46 \mathrm{aA}$ & $48,82 \mathrm{aA}$ \\
Adubação 3 & $52,60 \mathrm{abA}$ & $40,78 \mathrm{aA}$ \\
Adubação 4 & $48,30 \mathrm{abA}$ & $30,48 \mathrm{aB}$ \\
\hline Teor de Fe no solo antes da adubacão & 55,40 & 67,90
\end{tabular}

- as médias seguidas de pelo menos uma mesma letra minúscula na coluna e maiúscula na linha não diferem entre si em nível de $10 \%$ de probabilidade pelo Teste de Tukey 


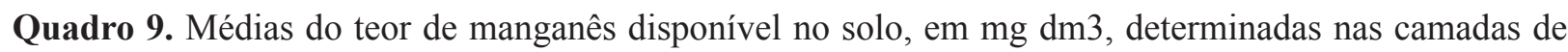
00,20 e 0,400,60 m, após adubação

\begin{tabular}{ccc}
\hline \multirow{2}{*}{ Adubação } & \multicolumn{2}{c}{ Camada (m) } \\
\cline { 2 - 3 } & $0-0,20$ & $0,40-0,60$ \\
\hline Adubação 1 & $49,32 \mathrm{aA}$ & $30,50 \mathrm{aB}$ \\
Adubação 2 & $44,36 \mathrm{aA}$ & $26,44 \mathrm{aB}$ \\
Adubação 3 & $39,64 \mathrm{aA}$ & $26,75 \mathrm{aB}$ \\
Adubação 4 & $36,52 \mathrm{aA}$ & $19,44 \mathrm{aB}$ \\
\hline Teor de Mn no solo antes da adubação & & 53,00
\end{tabular}

Teor de Mn no solo antes da adubação

53,30

53,00

- as médias seguidas de pelo menos uma mesma letra minúscula na coluna e maiúscula na linha não diferem entre si em nível de $10 \%$ de probabilidade pelo Teste de Tukey.

Diante dos resultados apresentados verificou-se que não ocorreu diferença estatística dos valores de manganês disponível no solo entre as parcelas submetidas às diferentes adubações, em ambas as camadas dosolo.

Os teores de manganês em todas as parcelas experimentais e em ambas as camadas foram classificados como alto, acima de $12 \mathrm{mg} \mathrm{dm}^{-}$ 3, segundo apresentado pela CFSEMG (1999). No entanto, ao comparar os resultados obtidos do teor de manganês disponível no solo antes da aplicação das adubações, verificou-se uma diminuição deste micronutriente no solo chegando a $31 \%$ na camada $0-0,20 \mathrm{~m}$ e $63 \%$ na camada $0,40-$ $0,60 \mathrm{~m}$ para a Adubação 4. Esta redução pode estar associada à absorção deste nutriente pelas plantas e ainda, segundo Malavolta (1997), à incorporação de matéria orgânica no solo pode ter formado precipitados de baixa mobilidade.

Observou-se que o teor de manganês determinado em amostras de solo coletadas na camada de $00,20 \mathrm{~m}$ foi superior em relação àquelas retiradas na camada de $0,400,60 \mathrm{~m}$, em todas as parcelas. Tal comportamento pode ser explicado pelo fato da incorporação da torta de mamona e da ARB ter sido realizada superficialmente e ainda pela baixa mobilidade deste elemento no perfil do solo, sendo retido na camada mais superficial.

Para os elementos $\mathrm{Fe}$ e $\mathrm{Mn}$ as legislações mencionadas anteriormente não estabelecem limites, possivelmente porque são encontrados em grandes concentrações no solo, o Fe, por exemplo é o micronutriente em maior concentração no solo (MALAVOLTA, 1980).

\section{CONCLUSÃO}

- A adubação com água residuária de bovinocultura foi capaz de reduzir a concentração do dos elementos $\mathrm{Zn}, \mathrm{Cu}, \mathrm{Fe}$ e $\mathrm{Mn}$ que a princípio apresentavam-se em concentrações elevadas no solo indicando níveis tóxicos;

- A Adubação 4 (100\% da dose de nitrogênio fornecida por meio da adubação com ARB) apresentou as maiores reduções nos teores de $\mathrm{Zn}, \mathrm{Cu}, \mathrm{Fe}$ e $\mathrm{Mn}$ em ambas as camadas;

- A matéria orgânica incorporada no solo pode ter atuado na quelação, complexação, formando precipitados de baixa mobilidade dosmicronutrientes $\mathrm{Zn}, \mathrm{Cu}, \mathrm{Fe}$ e $\mathrm{Mn}$;

- A adubação com ARB mostrou-se eficiente na redução de metais no solo, colaborando na redução de níveis críticos, que poderiam acarretar toxicidade às plantas.

\section{REFERÊNCIAS BIBLIOGRÁFICAS}

ALMEIDA, M.M.; SILVEIRA, E.T. Tratos culturais na cultura da figueira no sudoeste de Minas Gerais. Informe Agropecuário, Belo Horizonte, v.18, n.188, p.27-33, 1997.

AMERICAM PUBLIC HEALTH ASSOCIATION. Standart methods for the examination of water and wastewater. 19. ed. New York: APHA/WWA/ WPCR, 1995.

AMERICAM PUBLIC HEALTH ASSOCIATION. 
Water monitoring data collection standards. 2007. Disponível em: http://www.derm.qld.gov.au/water/ monitoring/pdf/wm_data_col_stds.pdf. Acesso em: 13 Set. 2012.

BARROS, F.M.; MARTINEZ, M.A.; NEVES, J.C.L.; MATOS, A.T.; SILVA, D.D. Características químicas do solo influenciadas pela adição de água residuária da suinocultura. Revista Brasileira de Engenharia Agrícola e Ambiental, Campina Grande, v.9, p.47-51, 2005. Suplemento.

BRASIL. Resolução CONAMA 357, de 17 de março de 2005. Conselho Nacional de Meio Ambiente. Disponível em: http://www.mma.gov. $\mathrm{br} /$ port/conama/legiabre.cfm?codlegi $=459$. Acesso em: 8 out. 2012.

BRASIL. Resolução CONAMA 420, de 28 de dezembro de 2009. Conselho Nacional de Meio Ambiente. Disponível em: http://www.mma.gov. br/port/conama/legiabre.cfm?codlegi $=620$. Acesso em: 8 out. 2012.

CARVALHO, A.J.C.; CAETANO, L.C.S. Efeito da adubação com boro e esterco bovino sobre a produtividade da figueira e as propriedades químicas do solo. Ciência Rural, Santa Maria, v.36, n.4, p.1150-1155, jul./ago. 2006.

CARVALHO, D.F.; SILVA, D.G.; ROCHA, H.S.; ALMEIDA, W.S.; SOUSA, E.S. Evapotranspiration and crop coefficient for potato in organic farming. Revista Engenharia Agrícola, Jaboticabal, v.33, p.201-211, 2013.

CARVALHO, D.F.; LIMA, M.E.; OLIVEIRA, A.D.; ROCHA, H.S.; GUERRA, J.G.M. Crop coefficient and water consumption of eggplant in no-tillage system and conventional soil preparation. Revista Engenharia Agrícola, Jaboticabal, v.32, p.784-793, 2012.

CARVALHO, H.P.; SILVA, I.J.O. Metais pesados presentes na água residuária de sistema de exploração leiteira do tipo "freestall". Revista Eletrônica Thesis, São Paulo, v.6, p.1-8, 2006.

COMISSÃO DE FERTILIDADE DO SOLO DO
ESTADO DE MINAS GERAIS. Recomendações para o uso de corretivos e fertilizantes $1999 \mathrm{em}$ Minas Gerais - $5^{\text {a }}$ Aproximação. Viçosa: CFSEMG, 1999. 359p.

DECHEN, A.R.; NACHTIGALL, G.R. Micronutrientes. In: FERNANDES, M. S. (Ed.). Nutrição mineral de plantas. Viçosa: Sociedade Brasileira de Ciência do Solo, 2006. p.327-354.

EMPRESA BRASILEIRA DE PESQUISA AGROPECUÁRIA. Manual de métodos de análise do solo. 2 ed. Rio de Janeiro: EMBRAPA, Centro Nacional de Pesquisa de Solos, 2011. 247p.

ERTHAL, V.J.T.; FERREIRA, P.A.; MATOS, A.T.; PEREIRA, O.G. Alterações físicas e químicas de um argissolo pela aplicação de água residuária de bovinocultura. Revista Brasileira de Engenharia Agrícola e Ambiental, Campina Grande, v.14, n.5, p.467-477, maio 2010.

FAQUIN, V. Nutrição Mineral de Plantas. Lavras, v. Lavras: UFLA/ FAEPE, 2005. 186p.

FERREIRA, D.F. Sisvar: a computer statistical analysis system. Ciência e Agrotecnologia, Lavras, v.35, p.1039-1042, 2011.

FREITAS, W.S. OLIVEIRA, R.A.; PINTO, F.A.; CECON, P.R.; GALVÃO, J.C.C. Efeito da aplicação de águas residuárias de suinocultura em solo cultivado com milho. Revista Engenharia na Agricultura, Viçosa, v.13, n.2, p.95-102, abr./jun. 2005.

LINDSAY, W.L. Chemical Equilibria in Soils. New York: John Wiley, 1979. 449p.

LO MONACO, P.A.; MATOS, A.T.; MARTINEZ, H.E.P.; FERREIRA, P.A.; RAMOS, M.M. Características químicas do solo após a fertirrigação do cafeeiro com águas residuárias da lavagem e descascamento de seus frutos. Irriga, Botucatu, v.14, n.3, p.348-364, jul./set. 2009.

MALAVOLTA, E. Elementos de nutrição mineral de plantas. Piracicaba: Agronômica Ceres, 1980. $251 \mathrm{p}$. 
MALAVOLTA, E.; VITTI, G.C.; OLIVEIRA, S.A. Avaliação do estado nutricional das plantas: princípios e aplicações. 2. ed. Piracicaba: Potafos, 1997. 319p.

MATOS, A.T. Disposição de águas residuárias no solo. Viçosa: AEAGRI, 2006. 142p. (Caderno Didático n. 38).

NACHTIGALL, G.R. et al. Copper concentration of vineyard soils as a function of $\mathrm{pH}$ variation and addition of poultry litter. Brazilian Archives of Biology and Technology, Curitiba, v.50, n.6, p.941-948, nov. 2007.

PEGORARO, R.F.; SILVA, I.R.; NOVAIS, R.F.; MENDONÇA, E.S.; GEBRIM, F.O.; MOREIRA, F.F. Fluxo difusivo e biodisponibilidade de zinco, cobre, ferro e manganês no solo: influência da calagem, textura do solo e resíduos vegetais. Revista Brasileira de Ciência do Solo, Viçosa, v.30, p.859-868, 2006.

QUEIROZ, F.M; MATOS, A.T.; PEREIRA, O.G.; OLIVEIRA, R.A.; LEMOS, A.F. Características químicas do solo e absorção de nutrientes por gramíneas em rampas de tratamento de águas residuárias da suinocultura. Revista Engenharia na Agricultura, Viçosa, v.12, n.2, p.77-90, abr./jun. 2004.

SANTOS, S.S.; SOARES, A.A.; MATOS, A.T.; MANTOVANI, E.C.; BATISTA, R.O. Efeitos da aplicação localizada de esgoto sanitário tratado nas características químicas do solo. Revista Engenharia na Agricultura, Viçosa, v.14 n.1, p.3238, jan./mar. 2006.

UNITED STATES ENVIRONMENTAL PROTECTION AGENCY - USEPA. Acid digestion of sediments, sludges and soils. Metod 3050b. Washington, EPA, 1996. 12p. 